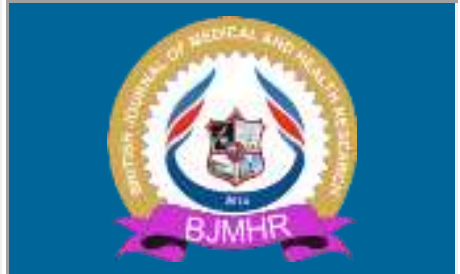

\title{
BJMHR
}

British Journal of Medical and Health Research Journal home page: www.bjmhr.com

\section{In vitro Evaluation of Biocompatibility and Cytotoxicity of Total Fill Bioceramic Root Repair material putty for endodontic use}

Chara Papadopoulou', Maria Georgopoulou' ${ }^{1}$, Ioannis Karoussis², Kyriaki Kyriakidou ${ }^{2}$, Triantafyllos Papadopoulos ${ }^{3}$

1.Department of Endodontics, School of Dentistry, National and Kapodistrian University of Athens

2.Department of Periodontics, School of Dentistry, National and Kapodistrian University of Athens

3.Department of Biomaterials, School of Dentistry, National and Kapodistrian University of Athens

\section{ABSTRACT}

The purpose of this study is to evaluate the biocompatibility and cytotoxicity of Total Fill (FKG Dentaire SA, Switzerland) and compare it with white MTA and Biodentine. The biocompatibility of Total Fill (FKG Dentaire SA, Switzerland) was tested in comparison with MTA (Tulsa Dental, Tulsa, OK) and Biodentine (Septodont, Saint Maur des Fosses, France) bioceramic materials. Cytotoxicity was investigated in terms of cell proliferation throughout the MTT assay, cell viability using FDA/PI test on MG63 pre-osteoblasts cell line for $24 \mathrm{~h}, 48 \mathrm{~h}$ and 72h. SEM micrographs have been used to describe the morphology of the cells seeded on the different ceramics. The alkaline phosphatase activity (ALP) was measured using the QUANTI-Blue method for experimental and control groups. As control the cells were seeded at the Tissue Culture Plastic (TCP). All the experiments were performed in triplicate in 3 independed runs and statistically analysed using 2-way ANOVA. MTT assay results showed a major rate of proliferation, after $72 \mathrm{~h}$ of seeding of the MG63 cells on the Total Fill sealing material than MTA and Biodentin. These results were in accordance with those obtained by the FDA/PI double staining and the SEM micrographs. All tested sealing materials performed an optimal biocompatibility, although Total Fill prevailed due to the characteristics of its solid state. In particular Total Fill presented an improved consistency which allowed the cells to populate the entire mass of the material, maintaining their viability.

Keywords: Biocompatibility, cytotoxicity, bioceramic, root canal sealer. 


\section{INTRODUCTION}

A major problem in general dentistry is the search for materials capable of interrupting communication between the oral cavity and the dental tissues, which have undergone some kind of dental intervention.

In many cases the conservative root canal treatment is not adequate to solve successfully inflammatory problems, whereas surgical procedure is necessary.

The main concern of the management of surgical procedures is the quality of retrofillings materials. The ideal retrofilling material should seal effectively the damaged area and also present biocompatible and osteogenic properties. (1). Although all available materials have some degree of dissolution that leads to microleakage, there is a critical point beyond which treatment is led to failure.

Different materials were used in the past. Amalgam, whose main drawbacks included corrosion, volumetric changes and gum discoloration (2-4), was replaced by materials with better properties, such as IRM, Super-EBA, composite resins and glass-ionomer cements $(3,5,6)$. Toxic effects, handling problems and effect of moisture (7) led Torabinejad et all (8) to introduce a new material called MTA (ProRoot MTA, Dentsply Endodontics, Tulsa, OK, USA), which chemically was a calcium trioxide complex and was claimed to block all communication channels $(9,10)$. Hydrophilic components are responsible for the physical and chemical properties of the material which set in the presence of moisture. Mixing the powder with sterile water, results in a colloidal gel achieving a pH around 12 within few hours (11). The clinical success of MTA is due to its biocompatibility, absence of cytotoxicity $(12,13)$, and ability to prevent bacterial microleakage (14). Studies on regenerative properties of MTA showed that osteoblasts and dentinoblasts of humans and animals cultured in contact with the material proliferated more rapidly than cells cultured without contact (15-19).

Although MTA was a real progress, many clinicians reported that its handling properties were far from ideal. The composition is difficult to remain stable due to the coagulation reaction. Another negative element is the long setting time of the material (20).

Recently, new bioceramic materials were introduced for use as retrograde fillings with promising properties. One of them is Total Fill Putty (FKG Dentaire SA, Switzerland), which is a pre-mixed bioceramic material ready for use in endodontic surgery. According to the manufacturer, it consists of calcium silicates, monobasic calcium phosphate, zirconium oxide, tantalum oxide, reinforcing agents and coagulation agents. Manufacturers claim that the material is highly biocompatible, hydrophilic, with a high $\mathrm{pH}$ (12), not stained, with a working time of about $30 \mathrm{~min}$ and is extremely irradiated, accordingly certified with European control regulations (CE 0470). In an in vitro study the material showed similar biocompatibility with 
MTA (21).

Another bioceramic material used with success is Biodentine (Septodont, Saint Maur des Fosses, France), which consists of tricalcium silicate, calcium carbonate, zirconium oxide in powder and calcium chloride as a catalyst and water as a reducing agent. Biodentine displays apatite formation as soon as it comes to contact with a phosphate solution, indicative of its bioactivity.

The objective of this study was to evaluate the biocompatibility and cytotoxicity of Total Fill Putty bioceramic material, using cell cultures of primitive human osteoblasts. Null hypothesis was that no negative reactions of the cells in contact with Total Fill Putty are recorded and that the biomaterial is not involved in cytotoxic reactions.

\section{MATERIALS AND METHOD}

Total Fill, (FKG Dentaire SA, Switzerland) was tested and compared to Mineral Trioxide Aggregate-MTA Angelus white (Tulsa Dental, Tulsa, OK) and Biodentine (Septodont, Saint Maur des Fossés, France).

\section{Cell cultures}

The human osteosarcoma cell line MG63 was purchased from (ATCC, EU). Cells were grown and maintained in standard conditions $37^{\circ} \mathrm{C}$ in humidified atmosphere containing $5 \% \mathrm{CO}_{2}$. Cells grown in DMEM low glucose supplemented with 10\% FBS and 1\% penicillinstreptomycin solution (Gibco, UK). MG63 cells were seeded onto the samples and to the cell tissue plastic (TCP) used as control, at the density of $1 \times 10^{4}$ cells $/ \mathrm{cm}^{2}$. All experiments were performed in triplicate in 3 independent runs and statistically analysed using 2-way ANOVA with $P$ values $(*)<.05$ were considered significant.

\section{Cell Cytotoxicity Assay}

The cell viability was assessed using an MTT assay. MG-63 cells were seeded onto the samples in a $24-w e l l$ plate for $24 \mathrm{~h}, 48 \mathrm{~h}$ and $72 \mathrm{~h}$. At each end point both the culture medium at the experimental and the control groups, was discharged and $200 \mathrm{~mL}$ MTT stock solution was added and incubated at $37^{\circ} \mathrm{C}$ with $5 \% \mathrm{CO}_{2}$ for $4 \mathrm{~h}$. After that, the MTT solution was removed and $2 \mathrm{~mL}$ of $96 \%$ isopropanol $\mathrm{HCl} 1 \mathrm{~N}$ was added to each well. The absorbance was recorded on a microplate reader (Beckman DU-640B, USA) at a wavelength of $570 \mathrm{~nm}$.

\section{Cell viability FDA/PI test}

In order to determine the cell viability on the seeded samples propidium iodide/fluorescein diacetate (PI/FDA) staining (Sigma-Aldrich, Germany) was performed. To prepare the FDA staining solution $1 \mathrm{mg} / \mathrm{mL}$ FDA were dissolved in acetone and further diluted to a concentration of $3 \mu \mathrm{g} / \mathrm{mL}$ in PBS. Then, the samples were rinsed with PBS before being counterstained with PI. To prepare the PI staining, $1 \mathrm{mg} / \mathrm{mL}$ PI was dissolved in distilled water 
and further diluted to a concentration of $0.1 \mathrm{mg} / \mathrm{mL}$ in PBS. After an additional washing step, the samples were analysed under a fluorescent microscope (Leica DM4000B, Germany).

\section{Scanning Electron Microscopy}

For SEM analysis, the samples were fixed with $3 \%$ glutaraldehyde $/ 0.1 \mathrm{M}$ sodium cacodylate buffer for $1 \mathrm{~h}$. Samples were then dehydrated in a graded series of ethanol solutions $(30 \%, 50 \%$, $70 \%, 95 \%$, and $100 \%(\mathrm{v} / \mathrm{v}))$ for $10 \mathrm{~min} / \mathrm{each}$, before being dried at room temperature. After the deposition of a thin gold layer $(\sim 10 \mathrm{~nm})$, the specimens were examined.

\section{Alkaline Phosphatase activity}

The ability of osteogenic differentiation of cells cultured in the specimens of the examined sealants was tested with the use of the enzyme alkaline phosphatase (ALP), which is one of the primary biochemical markers of bone differentiation of early osteoblasts. At the end of the cell cultures, 200ml of QUANTI-Blue (Invivogen, USA) solution and 20mL of supernatant from each sample are added and incubated for $30 \mathrm{~min}$ at room temperature. Optical absorption was recorded at a wavelength of $620-655 \mathrm{~nm}$ on an ELISA reader spectrophotometer (VersaMax Microplate Reader, Molecular Devices, USA).

\section{RESULTS AND DISCUSSION}

\section{Cell Cytotoxicity Assay}

MTT assay results (Fig. 1) showed a significant increase of the cells population seeded on Total fill in comparison of the number of cells present on MTA and Biodentine. In particular there was a statistical significant increase $(P=.002)$ of the cell number from the $24 \mathrm{~h}$ to the $72 \mathrm{~h}$. However no significant differences of the cell population have been noticed in the case of the Biodentin and MTA materials at the $48 \mathrm{~h}$ and $72 \mathrm{~h}$ respectively.

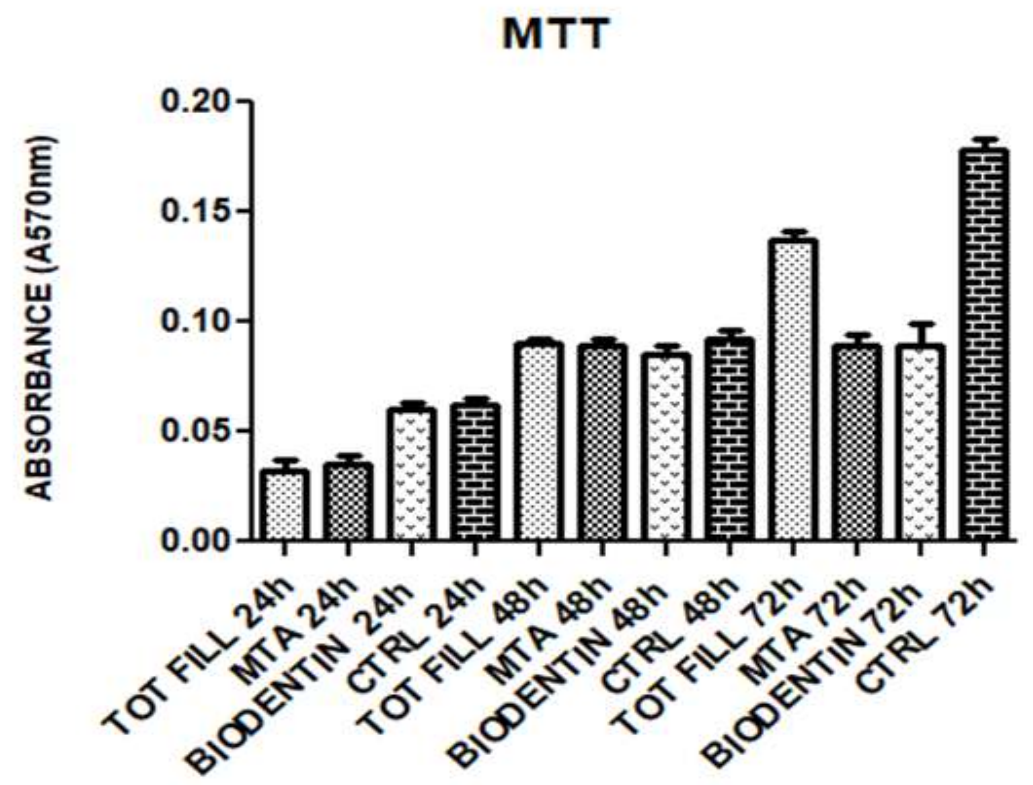

Figure 1. Diagram of cell behavior on the experimental and the control group in the MTT assay, after culture for $24 \mathrm{~h}, 48 \mathrm{~h}$ and $72 \mathrm{~h}$. 


\section{Cell viability FDA/PI test}

The FDA/PI images confirm that on the Total Fill the cells perform a better pattern of viability (Fig. 2). The presence of the green (viable) cells is predominant in the Total Fill material for all the experimental intervals instead of the cells growing on the MTA and Biodentine, where the number of dead (red) cells was recorded. The cell growth is in accordance with the results obtained by the MTT test.
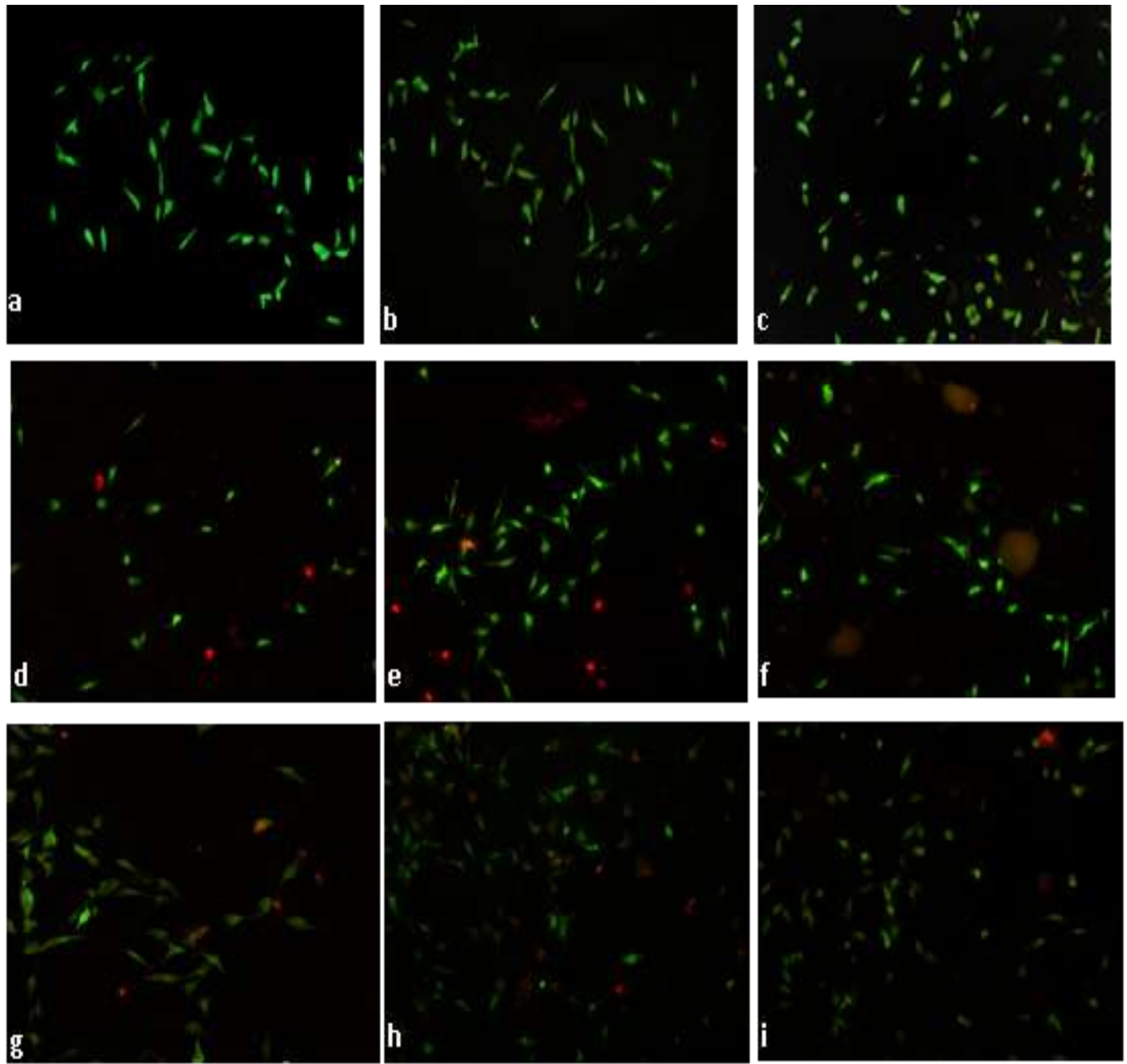

Figure 2. Representative images $(\mathbf{1 0 x})$ in fluorescence microscope of Total Fill after $\mathbf{2 4 h}$ (a), 48h (b) and 72h (c), Biodentine after 24h (d), 48h (e) and 72h (f) and MTA after 24h (g), 48h (h) and $72 \mathrm{~h}(\mathrm{i})$ of culture.

\section{Scanning Electron Microscopy}

From the observation of SEM micrographs, it is evident that in the Total Fill material the MG63 cells maintain their typical morphology. There are no signs of stressed cells during their effort to populate the material. The surface of the material itself appears to be homogeneous with a pore continuity which allows cell adhesion and communication between the cells through the cytoplasmic extensions developed during their permanence on it. Indeed during the MTT test the tetrazolium salts were not limited to the surface of Total Fill. The cells had penetrated all the material, and upon contacting the tetrazolium salts with isopropanol, formazan's "circular 
formations" appeared at the bottom of the plate where the material was attached. This finding proves that Total Fill permeability is definitely different from that of MTA and Biodentine, giving it a lead in selection.

In case of the MTA, the surface of the material is non-homogeneous and has large voids, so the cells are stressed during the adhesion process. This has an impact on their metabolism, resulting in less proliferation than those on Total Fill. A comparable situation is also seen with the surface of Biodentine where few and stressed cells were observed (Fig.3).
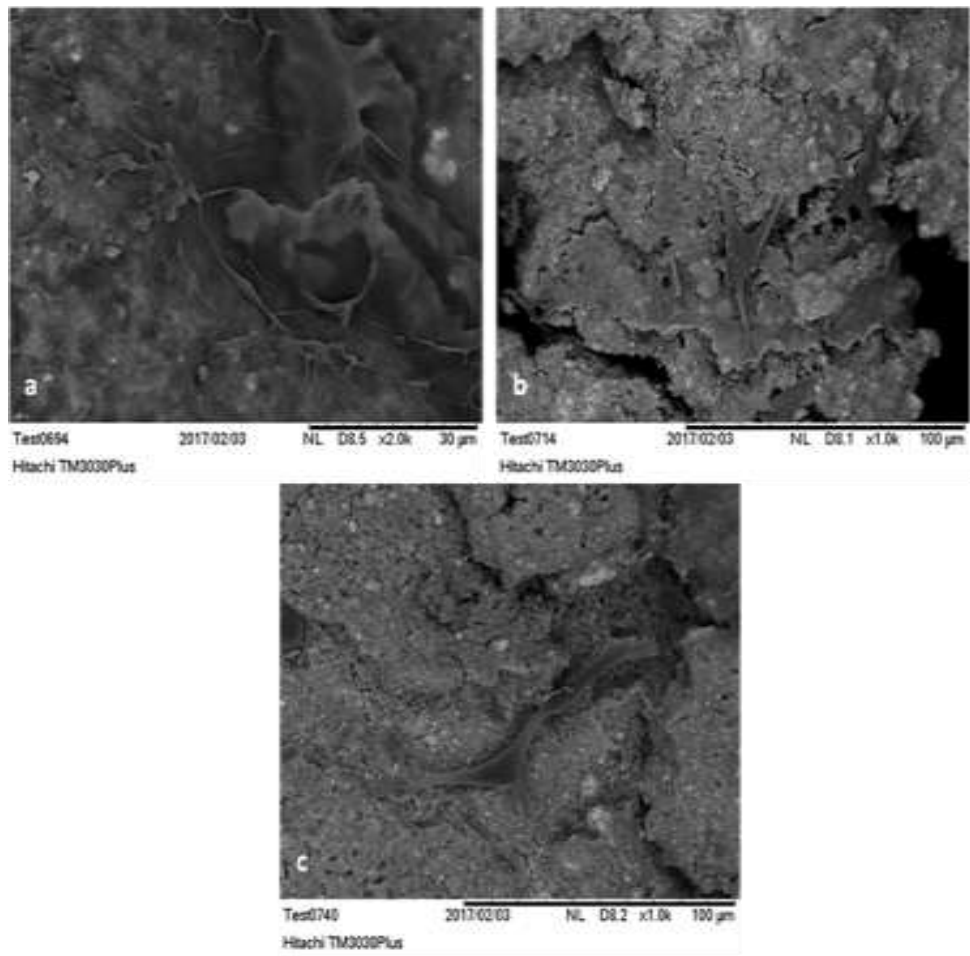

Figure 3. Micrographs (1000x) of Scanning Electron Microscopy of the Total Fill (a), MTA (b) Biodentin (c) samples seed with MG63 cells for $48 \mathrm{~h}$ in culture and Bottom surface of the culture plate where Total Fill MTT assay (d) took place.

In the case of the MTA material (Fig. 4a) the surface of the material is non-homogeneous and has large voids, so the cells are stressed during the adhesion process. This has an impact on their metabolism, resulting less proliferation than those on Total Fill. A comparable situation is also seen with the surface of Biodentine (4b), where few and stressed cells are observed.
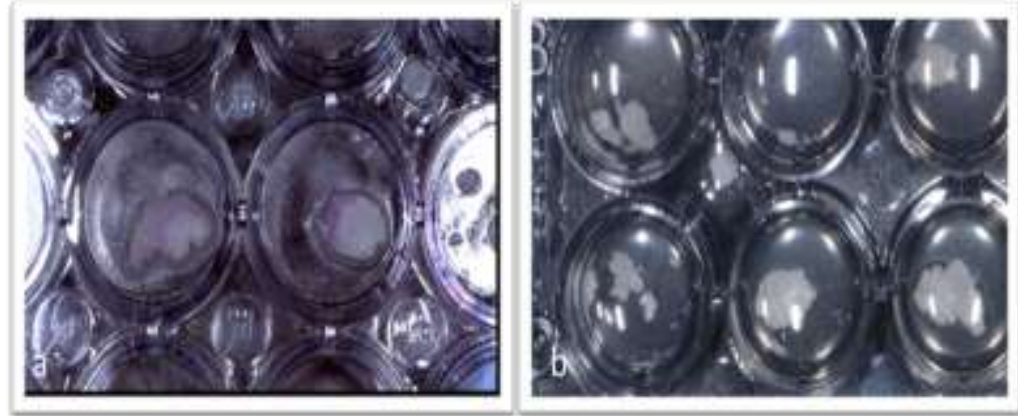
Figure 4. Bottom surface of the culture plate scarring Total Fill (a) and Biodentin, MTA (b) in which the MTT assay took place. Cell penetration is noticeable in Total Fill in contrary of the other two materials.

\section{Alkaline Phosphatase activity}

In terms of ALP levels no statistical significant differences were recorded among the implemented time points for all the tested materials. The only statistical significant increase was recorder for Total Fill between $24 \mathrm{~h}$ and $72 \mathrm{~h}$ of culture $(P=.0051)$ as it can be seen in figure

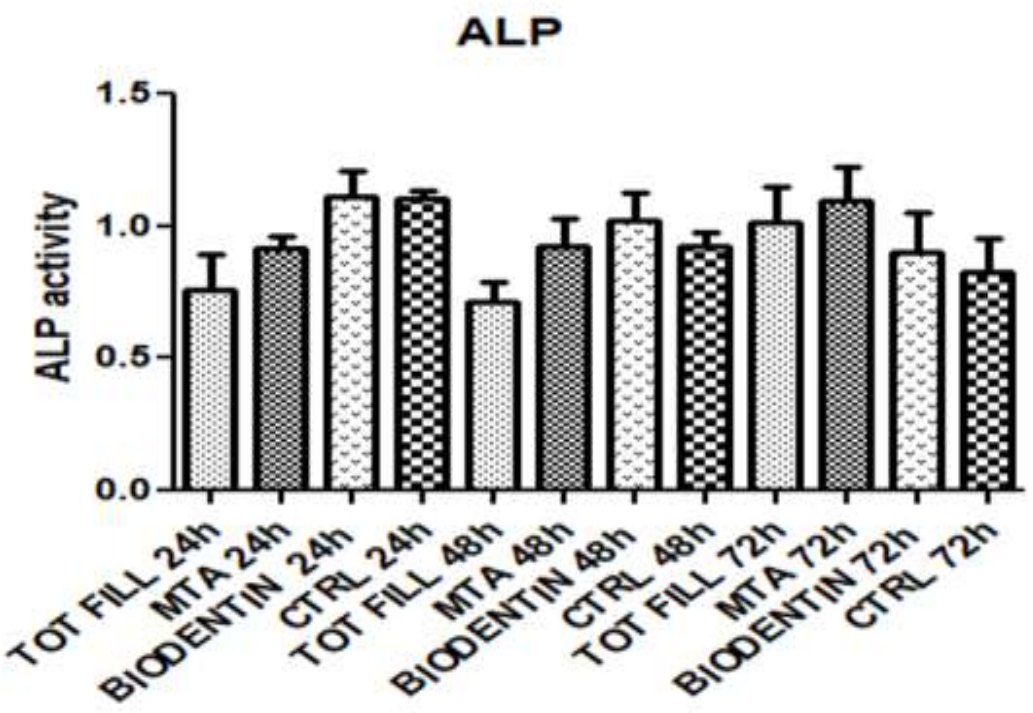

Figure 5. Graphic depiction of the alkaline phosphatase of the cells on the experimental and the control group, after culture for $24 \mathrm{~h}, 48 \mathrm{~h}$ and $72 \mathrm{~h}$.

\section{DISCUSSION}

Null hypothesis was confirmed, given that Total Fill demonstrate an optimal biocompatibility, no cytotoxicity for all the considered experimental time intervals whereas osteogenic properties where displayed.

Due to the lack of published studies on Total Fill, many of the comparisons of the results of the present study are related to Endosequence Root Repair Material, which is the same material produced in USA with different brand name.

The results of the present study, regarding the proliferation of the cells on Total Fill material, are in accordance with those obtained by Alanezi et al, (3) where the bioceramic Endosequence Root Pepair Material was tested for the same experimental culturing periods. In addition, in another study a similar ceramic material and the same cell line were used presenting excellent biocompatibility (18).

MTA as the gold standard has been tested in many studies and shows good biocompatibility and no cytoxicity.

According to Goldberg et al. (22), Biodentine shows good biocompatibility but was inferior compared to MTA, which is in accordance with the present study. 
Unlike MTA and Biodentine, Total fill is premixed from the manufacture, so there was no need for additional preparation. Both MTA and Biodentine were mixed according to the manufacture's directions.

The choice of the assays to perform has been done according to the general ISO 10993-5 guidelines. MTT assay is a standard and very reliable viability test which has been extensively used for cytoxicity purposes. In our study the results of the MTT assay are compared to those obtained by the FDA/PI apoptosis staining and are in accordance.

MTT assay results show a significant augmentation of the cells population seeded on Total fill in comparison of the number of cells present on the other two sealants. Indeed cell viability showed on the Fluorescent FDA/PI assay, was satisfactory in all the materials showing prevalence on the Total Fill surface. SEM micrographs confirmed that MG 63 cells morphology seeded on Total Fill material surface quantitatively prevail. In the case of the ALP levels no statistical significant differences were recorded among the implemented time points for all the tested materials. The only statistical significant increase was recorder for Total Fill between $24 \mathrm{~h}$ and $72 \mathrm{~h}$ of culture

\section{CONCLUSION}

Within the limitations of the present study, following conclusions can be drawn. Total Fill bioceramic material displayed excellent bioampatibility. In particular there was a statistical significant increase $(P=.002)$ of the cell number of Total Fill, compared to both MTA and Biodentine, from the $24 \mathrm{~h}$ to the $72 \mathrm{~h}$. However no significant differences of the cell population have been at the $48 \mathrm{~h}$ and $72 \mathrm{~h}$ respectively. From the observation of SEM micrographs, it is evident that in the Total Fill bioceramic material the MG63 cells maintain their typical morphology. Additionally, there are no signs of stressed cells during their effort to populate the material, in contrast to the others examined materials. ALP levels presented no statistical significant differences among the implemented time points for all the tested materials. The only statistical significant increase was recorder for Total Fill between $24 \mathrm{~h}$ and $72 \mathrm{~h}$ of culture $(P=.0051)$.

\section{REFERENCES}

1. Damas BA, Wheater MA, Bringas JS, Hoen MM. Cytotoxicity comparison of mineral trioxide aggregates and EndoSequence bioceramic root repair materials. Journal of endodontics. 2011;37(3):372-5.

2. Kontakiotis E, Nakou M, Georgopoulou M. In vitro study of the indirect action of calcium hydroxide on the anaerobic flora of the root canal. International endodontic journal. 1995;28(6):285-9. 
3. Alanezi AZ, Jiang J, Safavi KE, Spangberg LS, Zhu Q. Cytotoxicity evaluation of endosequence root repair material. Oral surgery, oral medicine, oral pathology, oral radiology, and endodontics. 2010;109(3):e122-5.

4. Camilleri J, Pitt Ford TR. Mineral trioxide aggregate: a review of the constituents and biological properties of the material. International endodontic journal. 2006;39(10):747-54.

5. Guimaraes BM, Vivan RR, Piazza B, Alcalde MP, Bramante CM, Duarte MAH. Chemical-physical Properties and Apatite-forming Ability of Mineral Trioxide Aggregate Flow. Journal of endodontics. 2017;43(10):1692-6.

6. Hansen SW, Marshall JG, Sedgley CM. Comparison of intracanal EndoSequence Root Repair Material and ProRoot MTA to induce $\mathrm{pH}$ changes in simulated root resorption defects over 4 weeks in matched pairs of human teeth. Journal of endodontics. 2011;37(4):502-6.

7. Adams DF. The American Academy of Periodontology. Journal of periodontology. 1996;67(2):177-9.

8. Parirokh M, Torabinejad M. Mineral trioxide aggregate: a comprehensive literature review--Part I: chemical, physical, and antibacterial properties. Journal of endodontics. 2010;36(1):16-27.

9. al LSe. Rationing Decisions: From Diversity to Consensus. Health Care Analysis. 1999;7(2):195-205.

10. Bodrumlu E. Biocompatibility of retrograde root filling materials: a review. Australian endodontic journal : the journal of the Australian Society of Endodontology Inc. 2008;34(1):30-5.

11. Camilleri J. Will Bioceramics be the Future Root Canal Filling Materials? Current Oral Health Reports. 2017;4(3):228-38.

12. Koh ET, Torabinejad M, Pitt Ford TR, Brady K, McDonald F. Mineral trioxide aggregate stimulates a biological response in human osteoblasts. Journal of biomedical materials research. 1997;37(3):432-9.

13. Pitt Ford TR, Andreasen JO, Dorn SO, Kariyawasam SP. Effect of various sealers with gutta-percha as root-end fillings on healing after replantation. Endodontics \& dental traumatology. 1996;12(1):33-7.

14. Shabahang S, Torabinejad M, Boyne PP, Abedi H, McMillan P. A comparative study of root-end induction using osteogenic protein-1, calcium hydroxide, and mineral trioxide aggregate in dogs. Journal of endodontics. 1999;25(1):1-5. 
15. Iordanoglou E PP, Nakou M. In vivo antibacterial effect of calcium hydroxide and camphorated paramonochlorophenol. International endodontic journal. 1998;31:198-9.

16. 10993-6 I. Biological evaluation of medical devices -- Part 6: Tests for local effects after implantation. 2016:29.

17. Jeevani E, Jayaprakash T, Bolla N, Vemuri S, Sunil C, Kalluru R. "Evaluation of sealing ability of MM-MTA, Endosequence, and biodentine as furcation repair materials: UV spectrophotometric analysis". Journal of Conservative Dentistry. 2014;17(4):340-3.

18. Jiang Y, Zheng Q, Zhou X, Gao Y, Huang D. A Comparative Study on Root Canal Repair Materials: A Cytocompatibility Assessment in L929 and MG63 Cells. The Scientific World Journal. 2014;2014:8.

19. Torabinejad M, Higa RK, McKendry DJ, Pitt Ford TR. Dye leakage of four root end filling materials: effects of blood contamination. Journal of endodontics. 1994;20(4):159-63.

20. Aouissi A, Al-Othman ZA, Al-Anezi H. Reactivity of heteropolymolybdates and heteropolytungstates in the cationic polymerization of styrene. Molecules. 2010;15(5):3319-28.

21. Saxena P, Gupta SK, Newaskar V. Biocompatibility of root-end filling materials: recent update. Restor Dent Endod. 2013;38(3):119-27.

22. Soundappan S, Sundaramurthy JL, Raghu S, Natanasabapathy V. Biodentine versus Mineral Trioxide Aggregate versus Intermediate Restorative Material for Retrograde Root End Filling: An Invitro Study. J Dent (Tehran). 2014;11(2):143-9.

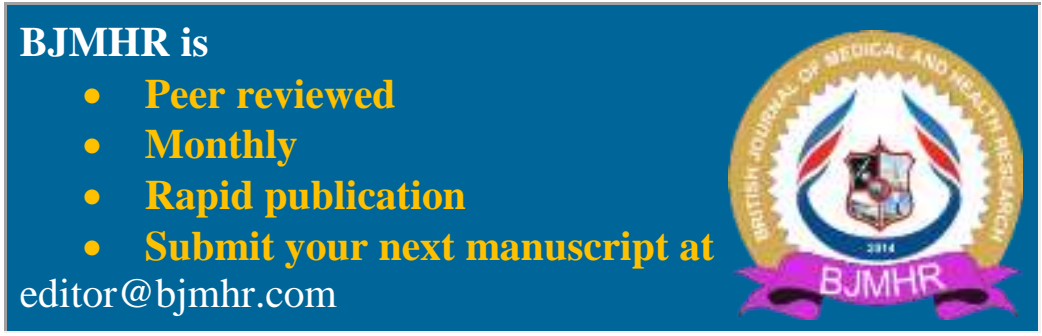

